\title{
The Impact of Voluntary IAS/IFRS Adoption on Medium Italian Private Entities: Implications for the Adoption of IFRS for SMEs
}

\author{
Paola Rossi, Thomas Hanni \\ University of Trento, Trento, Italy
}

\begin{abstract}
The EU Regulation 1606/2002 enhanced the financial statement comparability by requiring the International Financial Reporting Standards (IFRS) mandatory application. In Italy, the implementation of EU regulation stated that listed firms are required to prepare their financial statements in accordance with IFRS, then extended to private entities on a voluntary basis. The study examines the extent to which the change from Italian Generally Accepted Accounting Principles (GAAP) to IFRS has affected Italian small and medium-sized entities (SMEs). The results suggest that profit and equity reported under IFRS is higher than that reported under Italian GAAP and that the most relevant and frequent impacts are caused by the adoption of IAS 38, IAS 16, IAS 19, IAS 17, IAS 39, and IAS 18. This study can inform companies and policy makers of the consequences of IFRS adoption in those countries which intend to expand the application of IFRS more widely to smaller companies. Moreover, comparing the similarity and differences between full IFRS and IFRS for SMEs, this study supports the opinion that SMEs regulation cannot provide significant simplification especially designed for the needs of SMEs.
\end{abstract}

Keywords: international accounting, IFRS transition, financial reporting, medium enterprises

\section{Introduction}

The ongoing process of globalisation raises more and more the need for a harmonised and unified accounting language. In order to respond to these rising demands, the European Commission in 2002 published the regulation No. 1606, which requires all companies listed in European capital markets, from 2006 on, to prepare their financial statements according to International Accounting Standards (IAS)/International Financial Reporting Standards (IFRS) regulation. One crucial aspect of this mandatory application is that it refers only to public traded companies and therefore totally neglects the growing international integration of small and medium-sized entities (SMEs). In order to provide the SMEs with the necessary accounting framework to meet the requirements of an international integrated business, in 2009, the International Accounting Standards Board (IASB) released the IFRS for SMEs regulation. This new independent set of accounting standard should particularly suit the characteristics and needs of SMEs and be able to internationally harmonise their financial reporting.

Paola Rossi, Assistant Professor, Department of Economics and Management, University of Trento. Email: paola.rossi-1@unitn.it.

Thomas Hanni, Doctor, Department of Economics and Management, University of Trento. 
The IAS/IFRS are a group of accounting standards, elaborated by the IASB, with the aim "to develop a single set of high quality, understandable, enforceable and globally accepted financial reporting standards based upon clearly articulated principles" (IASB, 2014). In July 2002, the European Union (EU) released the regulation No. 1606/2002 which, from January 1, 2005 on, obligates all companies listed in EU financial markets to adopt IAS/IFRS standards for the preparation of their consolidated financial statements. The aim of such a regulation was "to ensure a high degree of transparency and comparability of financial statements and hence an efficient functioning of the Community capital market and of the Internal Market" (Article 4, Regulation No. 1606/2002, European Parliament). Since the obligation of adopting IAS/IFRS standards was implemented by regulation, it affected directly all listed companies of EU member states, without the need of converting the regulation in national law. However, in Article 6 of the regulation No. 1606/2002, the European Parliament gives the option to each member state to implement national regulations, which schedule the mandatory, or enable voluntary application of the IAS/IFRS also for the separate financial statements of listed companies and for non-public traded companies (Ernst \& Young, 2008).

The Italian legislature allows, from the financial year 2006 on, the voluntary application of the IAS/IFRS standards for the consolidated and also for the separate financial statement of non-listed companies. This option is not applicable for the separate financial statement of non-listed assurance companies and firms which prepare a simplified financial statement according to Article 2435-bis of the Italian Civil Code (Cordazzo, 2008).

Given this premise, the study aims to analyse the nature and the size of the differences between Italian GAAP and IFRS, examining the total and individual adjustments to IFRS in the reconciliations of net income and equity of SMEs in Italy. We have followed the methodology of Cortesi, Montani, and Tettamanzi (2009), calculating the percentages of increase/decrease in equity and net income for each company caused by the IAS/IFRS voluntary adoption.

The interest of focusing on SMEs is based on the existence of a large number of SMEs in Europe (99\%), as well as the recognition of their economic power and role as job providers, and incorporation of a large innovation potential (European Commission, 2010). In Italy, SMEs are considered as a strong component of Italian economy. Being demonstrated that the effect of IFRS transition was particularly marked, due to the distance between Italian GAAP and IFRS in listed companies (Bae, Tan, \& Welker, 2008), this could be reassessed in this study with reference to SMEs.

In previous literature, many studies have investigated the effects of IFRS on net income and net equity, but they have shown either positive or negative adjustments in profit, equity, and other accounting measures during the transitional period. In addition, no previous evidences exist on the implications of the adoption of IFRS on SMEs companies in Italy.

The results of this study are in line with the findings obtained from other Italian studies referred to listed companies, such as Cordazzo (2008) and Cortesi et al. (2009) which referred to Italian listed companies.

The observed adjustments to net income and equity derive mainly from the tax-driven nature of Italian GAAP and concern especially tangible/intangible assets, leasing, financial instruments, deferred tax recognition and employee benefits. 
Overall, the paper could provide a valuable contribution to the existing literature on the voluntary choice of IFRS, which is scarce for supporting the debate among policy makers and standard about the importance of IFRS application for unlisted firms. On the other hand, the findings of this paper are of direct relevance to Italian accounting regulators assessing the impact of IFRS on SMEs performance.

The remainder of the paper is organized as follows: Section 2 contains the analysis of institutional setting; Section 3 reviews prior literature; Section 4 present information about the sample and research methodology; Section 5 provides the results; Section 6 presents the discussion of the application of index of comparability; and Section 7 concludes the paper.

\section{Institutional Setting}

\section{The Adoption of IAS/IFRS in Italy}

Italy is a code law European country. It is characterised by a more conservative accounting system compared to IFRS. The scope of financial reporting is to satisfy the information needs of stakeholders as creditors, owners, employees, and government (Nobes \& Parker, 2008). In contrast, the IFRS system is investor-oriented. Moreover, the strong alignment between financial reporting and taxation motivates the Italian companies to use the managerial discretion in accounting method choice and to reduce the taxable income. Another characteristic of Italian system is that the banks are the major supplier of companies so the decision of companies to switch to IFRS can have an impact on their rating level.

Relating the differences between Italian accounting standards and IFRS, previous studies classify Italy as a "large GAAP differences" country (Marra, Mazzola, \& Prencipe, 2011) and empirical evidence shows that the transition to IFRS increases the net income and return on equity (ROE) of Italian companies (Cordazzo, 2013).

The mandatory adoption of IFRS is regulated by the Law No. 306/03 and implemented by the Legislative Decree No. 38/05. It states that firms can voluntarily apply IFRS on both consolidated and individual accounts. These firms are: firms under control of quoted firms, banks, financial intermediaries or insurance firms as well as other firms, which either prepare consolidated financial statements or are under the control of firms that prepare consolidated financial statements (Baldarelli, Demartini, \& Mošnja-Škare, 2007; Organismo Italiano di Contabilità, 2005; PwC, 2008). Further, IFRS are voluntarily applicable to separate financial statements of private firms that are not required to prepare consolidated financial statements only if their controlling entity presents consolidated accounts in accordance with IFRS. In contrast, firms that prepare individual accounts and are not under the control of a firm are excluded from any IFRS application.

\section{The Main Differences Between IAS and Italian GAAP}

The following section aims to provide a schematic overview of the main differences between Italian GAAP, full IFRS, and IFRS for SMEs. Comparative studies were mainly carried out by public institutions and consulting/auditing agencies. PwC (2009) and KPMG (2010), for instance, provided a detailed comparison between the full set of IAS/IFRS and IFRS for SMEs. On the basis of these studies, we present a comprehensive view over the three different accounting standards treated in this paper (see Tables 1 and 2). Moreover, the information is not to be considered exhaustive and may be integrated for a more detailed treatment by the cited literature. Further differences are, instead, treated more specifically in Section 5 of this paper. 
Table 1

Principal Differences Between Full IFRS and Italian GAAP

Full IFRS

Italian GAAP

Content of financial statements

Balance sheet, income statement, cash flow statement, changes Similar to IFRS; cash flow statement is not required, just in equity, accounting principles and disclosure; comparative recommended;

representation of at least two financial years.

Changes in equity part of the notes.

Structure of balance sheet

No predefined structure; requires just a minimal content;

distinct presentation of current and non-current.

Structure of income statement

No predefined structure; representation of costs by nature or

destination.

Extraordinary items

Not allowed as separate item in the income statement.

Required structure according to Article $2424 \mathrm{cc}$.

Revenue recognition

Based on various criteria which allow the recognition when risk,

benefits and the ownership have been transferred and the

amount of revenue can be measured reliably.

Revenues with multiple components

Each single component of revenue has to be accounted

separately; e.g., sales which include guarantees.

Required structure according to Article $2425 \mathrm{cc}$.

Construction contracts

Accounted on the percentage of completion method; completed Percentage of completion and completed contract method are contract method not allowed. allowed.

Interest expenses

\begin{tabular}{|l|l|l|}
\hline Recognized on the basis of accrual and effective yield. & Similar to IAS with the difference that methods which
\end{tabular}

Interest expenses which are connected to investments for

long-term construction projects have to be capitalized.

Employee benefits

Broader definition with respect to IAS; allowed as separate item in the income statement.

Required the projected unit credit method to evaluate the
Required the projected unit credit method to evaluate the employee termination indemnity) is considered an effective liabilities on an actuarial valuation. approximate the effective yield are allowed.

Acquisition of intangible assets

Capitalized if the required criteria are given; amortized on the All intangible assets have to be amortised; some have an basis of expected lifetime; assets with undefined lifetime are not expected lifetime of maximal five years; It is allowed to capitalised but annual impairment tests have to be carried out; capitalise start-up costs, advertising costs, and expansion costs. revaluations allowed in rare cases.

No revaluations allowed.

Internal production of intangible assets

Research costs are expensed to income statement when occurred; development costs can be capitalised when the rigorous criteria are given.

Similar to IFRS, with the exception that it is optional to expense or capitalise development costs.

Goodwill

Goodwill from business combinations is not subject to Goodwill arising from business combinations is amortised over amortization, but annual impairment tests have to be made.

five years (if certain criteria are met amortisation over maximal 20 years).

Tangible assets

It is possible to use cost or revaluation model to determine Just allowed to use historical cost method; revaluations are just amount of asset.

Leasing classification

Financial leasing if all risk and benefits of ownership are The legal form of the contract prevails the substance; when transferred. Substance prevails over form. financial leasing, information is required in the disclosure. 
(Table 1 continued)

\begin{tabular}{|c|c|}
\hline Full IFRS & Italian GAAP \\
\hline \multicolumn{2}{|l|}{ Accounting treatment by the lessee (financial leasing) } \\
\hline $\begin{array}{l}\text { Actual value of payments is recognised as tangible assets and of } \\
\text { the same amount as liability; the liability is progressively } \\
\text { reduced while the value of the asset is depreciated over } \\
\text { economic lifetime. }\end{array}$ & $\begin{array}{l}\text { All leasing are accounted as operating lease; leasing payments } \\
\text { are accounted as expense over lease term; for consolidated } \\
\text { statements is recommended the use of IAS 17, but not required; } \\
\text { If financial leasing information required in the disclosure. }\end{array}$ \\
\hline \multicolumn{2}{|c|}{ Impairment of assets } \\
\hline $\begin{array}{l}\text { If there are indications of a reduction of the value of the asset, } \\
\text { an impairment test needs to be undertaken. In case of a loss of } \\
\text { value, the asset has to be written off at the higher of the fair } \\
\text { value less costs to sell and the value of use; the value of use is } \\
\text { determined by the DCF method. The restoration of the value is } \\
\text { allowed in some specific cases but not for goodwill. }\end{array}$ & $\begin{array}{l}\text { Similar to IFRS, the reduction of the value of the asset has to be } \\
\text { durable. } \\
\text { The restoration of the value is required when the reasons for the } \\
\text { reduction of the value vanished. }\end{array}$ \\
\hline \multicolumn{2}{|l|}{ Investment property } \\
\hline \multicolumn{2}{|l|}{$\begin{array}{l}\text { Valuation on the basis of amortised cost or fair value. If fair } \\
\text { value method is used, eventual variations are recognised in } \\
\text { income statement. }\end{array}$} \\
\hline \multicolumn{2}{|l|}{ Inventory } \\
\hline $\begin{array}{l}\text { Evaluated at the lower of cost and net realizable value: The cost } \\
\text { is determined on the basis of FIFO or weighted average cost } \\
\text { method. LIFO is not allowed. }\end{array}$ & Similar to IFRS, LIFO is allowed. \\
\hline \multicolumn{2}{|l|}{ Biological assets } \\
\hline Measured at fair value less costs to sell at the point of harvest. & Fair value valuation is not permitted. \\
\hline \multicolumn{2}{|l|}{ Valuation of financial assets } \\
\hline $\begin{array}{l}\text { The valuation depends on the type of classification; investments } \\
\text { held to maturity, loans or credits are recorded at amortised cost } \\
\text { through imputation of their gains and losses in the income } \\
\text { statement; financial assets held for sale are valued at fair value } \\
\text { through the imputation of their gains and losses in net equity. }\end{array}$ & $\begin{array}{l}\text { Financial assets are valuated at cost reduced by durable losses } \\
\text { of value. Investments classified as current are valued at minor } \\
\text { of cost and realizable value. Financial institutions can evaluate } \\
\text { the current investments also at fair value. }\end{array}$ \\
\hline \multicolumn{2}{|l|}{ Provisions } \\
\hline $\begin{array}{l}\text { "Under IFRS a provision is made only if there is a current } \\
\text { obligation considered probable as a consequence of events } \\
\text { occurred before period-end deriving from legal or contractual } \\
\text { obligations or from behaviours or announcements of the } \\
\text { company that determine valid expectations in third parties, } \\
\text { provided that the amount of the liability can be reasonably } \\
\text { determined" (Cordazzo, 2008, p. 21). }\end{array}$ & $\begin{array}{l}\text { "Provisions for contingencies concern costs and charges of a } \\
\text { determined nature, whose existence is certain or probable, but } \\
\text { whose amounts or occurrence are not determinable at the } \\
\text { period-end" (Cordazzo, 2008, p. 21). }\end{array}$ \\
\hline
\end{tabular}

\section{Table 2}

\section{Principal Differences Between Full IFRS and IFRS for SMEs}

\begin{tabular}{|c|c|}
\hline Full IFRS & IFRS for SMEs \\
\hline \multicolumn{2}{|l|}{ Financial statements } \\
\hline $\begin{array}{l}\text { Balance sheet, income statement, cash flow statement, changes } \\
\text { in equity, accounting principles and disclosure; comparative } \\
\text { representation of at least two financial years. }\end{array}$ & $\begin{array}{l}\text { Same requirements with the only difference that under certai } \\
\text { circumstances a combined statement of income and retaine } \\
\text { earnings can be prepared instead. }\end{array}$ \\
\hline \multicolumn{2}{|c|}{ Business combinations } \\
\hline $\begin{array}{l}\text { According to IFRS } 3 \text {, transaction costs are not part of the } \\
\text { acquisition costs. } \\
\text { Contingent considerations }{ }^{1} \text { are recorded independently of the } \\
\text { payment probability. }\end{array}$ & $\begin{array}{l}\text { Transaction costs are part of the acquisition costs. } \\
\text { Contingent considerations which are probably paid and whos } \\
\text { fair value can be measured reliable are part of the acquisitio } \\
\text { costs. }\end{array}$ \\
\hline
\end{tabular}

\footnotetext{
1 "Contingent consideration is an obligation of the acquiring entity to transfer additional assets or equity interests to the former owners of an acquiree. The terms under which this consideration will be calculated and paid is part of the acquisition agreement. The consideration will only be paid if specified future events occur or conditions are met. The amount of contingent consideration paid is recorded at its fair value in the accounting records of the acquiring entity" (Retrieved from http://www.accountingtools.com/contingent-consideration-defin).
} 
(Table 2 continued)

\begin{tabular}{|c|c|}
\hline Full IFRS & IFRS for SMEs \\
\hline \multicolumn{2}{|l|}{ Investments in associates and joint ventures } \\
\hline $\begin{array}{l}\text { For the accounting of investments in associates the equity method } \\
\text { is used. Cost and fair value method are not allowed (besides in } \\
\text { separate statements). For jointly controlled entities, the equity } \\
\text { method and the proportionate consolidation method are permitted. }\end{array}$ & $\begin{array}{l}\text { For the accounting of investments in associates or jointl } \\
\text { controlled entities, the fair value, the cost or the equity mode } \\
\text { can be used. }\end{array}$ \\
\hline \multicolumn{2}{|l|}{ Expense recognition } \\
\hline $\begin{array}{l}\text { Research cost cannot be capitalised, development and } \\
\text { borrowing costs are capitalised when specific criteria are met. }\end{array}$ & $\begin{array}{l}\text { Research, development and borrowing costs are recognized a } \\
\text { expenses. }\end{array}$ \\
\hline \multicolumn{2}{|c|}{ Financial instruments - derivatives and hedging } \\
\hline $\begin{array}{l}\text { Financial instruments are divided into five different categories: } \\
\text { (1) Financial assets or liabilities at fair value; } \\
\text { (2) Value through profit or loss; } \\
\text { (3) Held-to-maturity investments; } \\
\text { (4) Loans and receivables; } \\
\text { (5) Available-for-sale financial assets. }\end{array}$ & $\begin{array}{l}\text { Two different sections: } \\
\text { First section for non-complex/basic financial instruments, such } \\
\text { as simple payables and receivables; mostly measured at } \\
\text { amortised cost; } \\
\text { Second section for more complex financial instruments } \\
\text { generally measured at fair value through profits or loss. }\end{array}$ \\
\hline \multicolumn{2}{|l|}{ Non-financial assets and goodwill } \\
\hline $\begin{array}{l}\text { For intangible and tangible assets, the cost and the revaluation } \\
\text { model is permitted. Goodwill and other intangible with } \\
\text { indefinite lives are not amortised and annual impairment tests } \\
\text { are required. }\end{array}$ & $\begin{array}{l}\text { Only the cost model is permitted and all intangible assets } \\
\text { (goodwill included) have infinite lives and have to be amortised. } \\
\text { The impairment test is required only when there are indicators } \\
\text { of a loss in value of the asset. }\end{array}$ \\
\hline $\begin{array}{l}\text { For the measurement of investment property, the cost model or } \\
\text { the fair value method can be used. }\end{array}$ & $\begin{array}{l}\text { The fair value method is used, if the value can be easily } \\
\text { measured. }\end{array}$ \\
\hline $\begin{array}{l}\text { IFRS } 5 \text { requires noncurrent assets which are held to sale, to be } \\
\text { classified as such and presented separately. They are not } \\
\text { depreciated and measured at the lower of carrying amount and } \\
\text { fair value less cost to sell. }\end{array}$ & $\begin{array}{l}\text { Assets held for sale are not treated in the IFRS for SME } \\
\text { Selling assets is considered as an impairment indicator. }\end{array}$ \\
\hline \multicolumn{2}{|l|}{ Employee benefits } \\
\hline $\begin{array}{l}\text { According to IAS 19, "actuarial gains or losses can be } \\
\text { recognised immediately or amortised into profit or loss over the } \\
\text { expected remaining working lives of participating employees". }\end{array}$ & $\begin{array}{l}\text { Immediate recognition is required and the expense has to } b \\
\text { split in the various components. }\end{array}$ \\
\hline $\begin{array}{l}\text { The accrued benefit valuation method has to be used for } \\
\text { computing defined benefit obligations. }\end{array}$ & $\begin{array}{l}\text { "The circumstance-driven approach is applicable, which means } \\
\text { that the use of an accrued benefit valuation method (the } \\
\text { projected unit credit method) is required if the information that } \\
\text { is needed to make such a calculation is already available, or } \\
\text { if it can be obtained without undue cost or effort. If not, } \\
\text { simplifications are permitted in which future salary progression, } \\
\text { future service or possible mortality during an employee's period } \\
\text { of service are not considered" (PwC, 2009, p. 8). }\end{array}$ \\
\hline
\end{tabular}

\section{Literature Review}

\section{The Impact of IAS/IFRS on Listed Companies}

Many studies have investigated the effects of IFRS on EU listed companies, but they have reported different results, demonstrating the inconsistency of the previous literature review in this field.

In the UK, Aisbitt (2006) found a little effect, for the FTSE 100 companies, of IFRS on equity, while Ormrod and Taylor (2004) showed a $39 \%$ increase in the overall profit and $23 \%$ decrease in equity as compared to UK GAAP. Furthermore, investigating the impact of disclosure under IFRS 1 in the UK, Italy, and Ireland, Dunne, Fifield, Finningham, Fox, Hannah, Helliar, Power, and Veneziani (2008) showed respectively, positive and negative adjustments to profit and equity in the three countries. Finally, Dunne et al. (2008) evidenced that the standards that caused the most differences were: IAS 8, IAS 12, IAS 19, IAS 36, IAS 38, IAS 39, IFRS 2, and IFRS 3. Similarly, Fifield, Finningham, Fox, Power, and Veneziani (2011) made an analysis of the transition to IFRS in the UK, Ireland, and Italy, applying the Gray's comparability index; the conclusion is that for the sample 
under study, the IFRS 2004 profit is on average higher than according to British, Irish, and Italian regulations. As for the transition to IFRS in 2005 over equities, Fifield et al. (2011) found different situations in the three studied countries: if in the case of the UK and Italy equity gets higher, in the case of Ireland equity gets lower.

Other studies have also examined the impact of IFRS on the financial statements of companies in different countries. As for Belgium, Jermakowicz (2004) suggested his belief that the impact of applying the IFRS is significant on equity and the net income. In France, Marchal, Boukari, and Cayssials (2007) studied the impact of the transition to IFRS over the data published by 291 listed French non-financial groups and they found, overall, a limited decrease (2\%) of equity, even if for two-thirds of the studied population equity increases; the net income rises considerably - on average by $38 \%$ (for $73 \%$ cases the net income rose); the leverage also rises on average by $16 \%$. In Germany, Hung and Subramanyam (2004) found a confirmation of the orientation of German accounting to prudence and earnings smoothing: IFRS total assets, equity and net income exceed generally and significantly the same values calculated according to German standards.

In Italy, Cordazzo (2008) has analysed the effect of IAS/IFRS implementation on shareholders equity and on net income of 178 Italian listed companies. According to her results, Italian net income increases on average by $14.25 \%$ and shareholders equity on average by $5.02 \%$. Furthermore, the author highlighted that the most invasive standards for net income and shareholders equity were: IFRS 3, IAS 19, IAS 39, IAS 38, IAS 12, and IAS 16. Another relevant research concerning this topic was carried out by Cortesi et al. (2009). Based on the MIB sample, they analysed the impact of IAS/IFRS implementation on net income and net equity of 160 firms. Besides the measurement of the overall effect on net income and net equity, they were able to value the impact of each single standard on the total differences. The study allows the identification of the main drivers for the changes in net equity and net income. Their results show that the most impact was caused by IAS 38 which treats the intangible assets. This single standard provoked an increase in net equity by $3.5 \%$. IAS 16 had a similar influence $(2.7 \%)$ which deals with property, plant, and equipment. The main negative effects were generated by IAS 19 (Employee's Benefits), IAS 32/39 (Financial Instruments), and IAS 18 (Revenue). Surprisingly, not all standards which had a major impact on net equity also had such impact on net income. IAS 16 for example plays a minor role with respect to net income. Most important drivers were IAS 38 (Intangible Assets), IAS 27 (Consolidated and Separate Financial Statements), IAS 32/39 (Financial Instruments), and IAS 18 (Revenue).

The above studies are referred to the listed companies. In this study, it is expected that, considering the differences in size, ownership, and governance structure, the impact of IFRS on equity and income may be smaller than those on companies listed on the main markets.

\section{Literature Review About IFRS for SMEs}

Reviewing the main literature regarding the IFRS for SMEs, it can be observed that this relative recent topic has caused a lively discussion among researchers and experts in the last years. The research objects of these papers differ a lot and a general valid classification is therefore not simple. Nevertheless, it can be observed that the main issues addressed are related to the development process of IFRS for SMEs, to international and national convergence, and to the effects of implementation in countries. Moreover, a relevant number of studies discuss the general need of the standard and its ability to effectively fit the particular requirements of SMEs. Most of these researches consist of questionnaires or comparative studies whereas quantitative empirical studies are quite rare. Since the adoption of IFRS for SMEs is not yet allowed in the EU, there are no, as far as known, empirical studies which analyse or simulate the effect of IAS implementation on accounting figures or performance. 
According to the IASB, the standard-setting of the new IFRS for SMEs set occurred with a strong insolvent of the main stakeholder. In June 2004, the IAS published a discussion paper which represents the starting point of a 5-year long consultation process. But also after the IASB published the IFRS for SMEs in July 2009, the participation of the main IFRS for SMEs stakeholder kept going. Several times the IASB asked for comments regarding the new bundle of standards on which they then based the various amendments. The most recent example for this consultation process is based on the exposure draft issued in October 2013 for which the IASB has received and analysed 57 comment letters (IASB, 2014). A similar questionnaire, elaborated by the European Commission, took place between November 2009 and March 2010. The aim of the consultation was to obtain information about the opinion of EU stakeholders on the IFRS for SMEs (Quagli \& Paoloni, 2012). The responses of the questionnaire were analysed by the European Commission in the "Summary Report of the Responses Received to the Commission's Consultation on the International Financial Reporting Standard for Small and Medium-Sized Entities" (European Commission, 2010). In this report, the European Commission stated that the overall opinions about IFRS for SMEs were divergent. Supporters highlight that SMEs could draw potential benefits from the application of IFRS for SMEs, such as increasing international comparability of financial statements, expanded cross-border trade, increase of foreign investments and merger and acquisition activity, decrease in cost of capital; Opponents on the other hand stress the complexity of the standard, the high implementation cost, the incongruity of the standard with national tax laws, and the fact that only local or national orientated firms do not benefit from the adoption of international standards (European Commission, 2010). Based on the same set of data, Quagli and Paoloni (2012) carried out a further analysis. They highlighted that there is a significant spread between the opinions of preparers and users. The users present a strong aversion to the new set of international standards for SMEs whereas users are more favourable. In addition, a significant gap between different member states can be observed. Anglo and Nordic countries tend to be IFRS for SMEs friendly, whereas German-speaking and Latin countries are more resistant (Koumanakos \& Alexandrou, 2010). The strong objection of German-speaking countries was also proved by a survey of Eierle and Haller (2009).

Similar studies were already carried out by Paoloni (2006), Schiebel (2007), and Di Pietra, Evans, Chevy, Cisi, Eierle, and Jarvis (2008) which mainly highlighted that the level of participation of users in the consultation process was relatively low. The vast majority of comments arrived from audit firms, public institutions, and standard-setting agencies. This fact shows the IASB promoted participation of users in the standard-setting is not the case. Moreover, a disinterest in the topic can be traced from this part of stakeholders. Based on those findings especially Di Pietra et al. (2008) criticized the IFRS for SMEs from the absence of a deeper study of user needs. Such deeper studies of user needs were conducted by Cole, Breesch, and Branson (2009) or Deaconu, Nistor, and Popa (2009). They evidenced that the vast majority of stakeholders were interested in a harmonisation of financial reporting, but they mainly required a relative low level of complexity of the standards.

In general, the IFRS for SMEs was and still is confronted with much criticism. In their research, Sava, Marza, and Esanu (2013) pointed out major problems regarding the new bundle of standards. A first issue concerns the definition of SMEs given in the standards. As already mentioned above, this definition varies significantly from the definition given by the EU or similar institutions. Moreover, studies such as Barker and Noonan (1995) and Demartini (2005) showed that the SMEs itself are not to be considered a homogenous group and therefore more detailed sub-categories are required. For this reason, Deaconu, Popa, Buiga, and Fulop (2009) considered a unique standard, which refers to the SMEs in general as not reasonable. Another problem consists of the high cost of implementation. Especially, Pascu and Vasiliu (2011) highlighted the high cost for SMEs adopting IFRS for SMEs. As the main issues driving the costs, they pointed out: 
(1) The complexity of standard with respect to local GAAP;

(2) Difficulty of breaking with local accounting tradition;

(3) Obligation of preparing a second set of statement for tax purpose;

(4) Locally orientated company does not benefit.

In line with the already stated criticism, Ikäheimo, Ojala, Riistama, and Stening (2010) discovered that forced adoption of IFRS for SMEs is likely to lead to extra cost for adopting companies and accounting/auditing firms. Moreover, the researchers evidenced that global or international integrated SMEs are likely to benefit from an application of IFRS for SMEs, whereas local orientated companies will not.

Despite the cited critics, some research papers highlight the positive effects of IFRS for SMEs. Common benefits, stated by analysis such as Pascu and Vasiliu (2011), are:

(1) Increased international comparability;

(2) Mobility of audit and accounting service in the European Union;

(3) Benefits for stakeholders due to harmonized information;

(4) Facilitation of cross border trade;

(5) Increased confidence in accounting/financial statements.

An interesting advantage has been underlined by Grosu and Bostan (2010) who analysed the process of IFRS for SMEs implementation in Romania. They concluded that in countries such as Romania, where the local bodies are not able to provide high-quality accounting standards, the implementation of international accounting standards is an adequate tool to create an efficient reporting framework. This consideration may also explain the huge success of IFRS for SMEs in emerging markets.

\section{Methodology}

\section{Sample}

As mentioned at the beginning of this paper, the study refers to Italian medium-sized entities. Although the IFRS for SMEs refers to all companies which do not have public accountability, for this analysis, the definition of medium-sized entities given by the EU was applied. Reasons for that are several. First of all, in order to be able to carry out the analysis, it was necessary to identify a homogenous group with a reasonable number of companies. Referring to all companies that do not have public accountability and present IAS/IFRS financial statements (about 1,200 companies in Italy) in this context would have been beyond the aim of this paper. Even a random selected sample of those companies would probably lead to non-accurate results since it would consist of companies which range from micronized entities to huge multinational non-listed enterprises. Secondly, as mentioned earlier, there exists an ongoing debate on the definition of SMEs used by the IASB. A standard which refers to such a broad variety of companies could never fit the special needs of all. By applying the definition of medium-sized entities given by the EU, it is possible to homogenize the set and then to measure the adequateness of IFRS for SMEs according to their needs.

Italian private and active firms meeting the requirements for the voluntary IFRS adoption are selected and their data are collected from the AIDA Database from 2005 to 2014. Firms operating in specific sectors (financial, insurance, pension funding, real estate, rental, education, public, leasing, legal and accounting sector) are excluded due to their specific accounting requirements. The initial sample is composed by 146 industrial companies. As Table 3 shows, this set of companies had to be reduced by the enterprises which had no transition from Italian GAAP to IAS/IFRS, since they have applied the international accounting standards since 
their constitution. By analysing the so identified companies, it was possible to observe that one company was wrongly classified as IAS/IFRS preparer but in reality did not do. Moreover, two companies had passed the search criteria even though they exceed the given limits. From the remaining 122 companies, 15 separate financial statements were not available at AIDA, 13 enterprises had no reconciliation statement available, and one financial statement was not legible. The resulting final sample consists of 93 firms operating in various sectors.

Table 3

Sample Selection Criteria

\begin{tabular}{lc}
\hline Criteria & No. \\
\hline Industrial companies & 146 \\
No transition from Italian GAAP to IAS & -21 \\
Wrongly classified as IAS preparer & -1 \\
Financial statement not available & -15 \\
Reconciliation statement not available & -13 \\
Not legible & -1 \\
Over stated limits & -2 \\
Total number of analysed companies & 93 \\
\hline
\end{tabular}

The base of the undertaken analysis is formed by the reconciliation statements because IFRS 1 requires that "an entity shall explain how the transition from previous GAAP to IFRSs affected its reported financial position, financial performance and cash flows". Furthermore, it specifies that a “... company's first IFRS financial statements should include a reconciliation of shareholders' equity and net income...”. In Italy, the content of such document is not specified and therefore the form and accuracy of those statements, especially in non-quoted firms, can vary significantly. The Italian Securities and Exchange Commission (CONSOB) only recommends that the statement should provide complete and useful information in order to understand the impact of the new accounting standards on financial performance and accounting figures. The reconciliation statement itself can be disclosed after transition date, in the half-year or quarterly-year report or in the annual report. Table 4 represents the ideal statement, which allows not only individuating the difference of shareholders equity and net income under Italian GAAP and IAS/IFRS but also measuring the impact of each single IAS/IFRS standard.

Table 4

Translated Reconciliation Statement of DELTA MED S.P.A. 2012

\begin{tabular}{llll}
\hline Adjustments & $\begin{array}{l}\text { Shareholders' equity at } \\
\text { January 1, 2011 }\end{array}$ & $\begin{array}{l}\text { Net income } \\
\text { year 2011 }\end{array}$ & $\begin{array}{l}\text { Shareholders' equity at } \\
\text { December 31, 2011 }\end{array}$ \\
\hline According to Italian GAAP & $8,984,723 €$ & $77,740 €$ & $9,062,463 €$ \\
IFRS 3: Goodwill & $3,912,723 €$ & $734,832 €$ & $4,647,555 €$ \\
IAS 38: Intangible Assets & $(45,825) €$ & $22,305 €$ & $(23,520) €$ \\
IAS 17: Leasing & $194,798 €$ & $243,701 €$ & $438,499 €$ \\
IAS 19: Employee Benefits & $13,218 €$ & $(11,499) €$ & $1,719 €$ \\
IAS 39: Financial Instruments & $(70,070) €$ & $57,197 €$ & $-12,873 €$ \\
Tax effects of adjustments & $(36,964) €$ & $(91,240) €$ & $-128,204 €$ \\
Total adjustments & $3,967,880 €$ & $955,296 €$ & $4,923,176 €$ \\
According to IAS/IFRS & $12,952,603 €$ & $1,033,036 €$ & $13,985,639 €$ \\
\hline
\end{tabular}




\section{Research Method}

Following the methodology used by Cortesi et al. (2009), we have calculated for each company's financial statement the change occurred to the equity and net income using the formulas below and then we have computed the percentage of increase or decrease due to the IAS/IFRS voluntary adoption:

$$
\frac{E Q U I T Y_{I A S}-E Q U I T Y_{I T G A A P}}{E Q U I T Y_{I T G A A P}} \frac{P R O F I T_{I A S}-P R O F I T_{\text {ITGAAP }}}{P R O F I T_{\text {ITGAAP }}}
$$

\section{Results}

Table 5 shows the overall impact of the implementation of IAS/IFRS on shareholders' equity and net income. Moreover, it provides the relative impact of each single IAS/IFRS standard on these two figures.

Table 5

Percentage Variation of Shareholders' Equity and Net Income

\begin{tabular}{|c|c|c|c|c|c|}
\hline Description & $N$ & Result & Description & $N$ & Result \\
\hline Var. Shareholders' equity & 93 & $6.27 \%$ & Var. Net income & 93 & $14.43 \%$ \\
\hline Var. Shareholders' equity/IAS & 85 & $7.11 \%$ & Var. Net income/IAS & 87 & $14.42 \%$ \\
\hline IAS $38 / 36$ & 66 & $4.36 \%$ & IAS $38 / 36$ & 68 & $29.06 \%$ \\
\hline IAS 19 & 76 & $0.38 \%$ & IAS 19 & 74 & $-0.51 \%$ \\
\hline IAS 12 & 58 & $-2.07 \%$ & IAS 12 & 60 & $-5.61 \%$ \\
\hline IFRS 3 & 7 & $1.02 \%$ & IFRS 3 & 6 & $-5.12 \%$ \\
\hline IAS $16 / 36$ & 32 & $3.26 \%$ & IAS 16 & 31 & $2.45 \%$ \\
\hline IAS 37 & 20 & $0.19 \%$ & IAS 37 & 16 & $-0.22 \%$ \\
\hline IAS 39/32 & 32 & $-0.34 \%$ & IAS $39 / 32$ & 28 & $-0.39 \%$ \\
\hline IAS 2 & 9 & $0.16 \%$ & IAS 2 & 7 & $0.2 \%$ \\
\hline IAS 17 & 33 & $0.41 \%$ & IAS 17 & 34 & $4.55 \%$ \\
\hline IAS 28 & 1 & $0.00 \%$ & IAS 28 & 1 & $0.02 \%$ \\
\hline IAS 18 & 4 & $-0.23 \%$ & IAS 18 & 5 & $-8.67 \%$ \\
\hline IAS 27 & 4 & $-0.02 \%$ & IAS 27 & 3 & $-0.18 \%$ \\
\hline IAS 11 & 4 & $-0.06 \%$ & IAS 11 & 6 & $-0.73 \%$ \\
\hline IAS 8 & 3 & $-0.18 \%$ & IAS 8 & 3 & $-0.83 \%$ \\
\hline IAS 20 & 7 & $0.08 \%$ & IAS 20 & 6 & $0.55 \%$ \\
\hline IAS 1 & 3 & $0.01 \%$ & IAS 1 & 1 & $0.08 \%$ \\
\hline IAS 23 & 4 & $0.14 \%$ & IAS 23 & 3 & $-0.23 \%$ \\
\hline
\end{tabular}

In general, the adoption of IAS/IFRS caused on average an increase of shareholders' equity by $6.27 \%$ and of net income by $14.43 \%$. By considering only those companies for which an analysis per single IAS/IFRS standard was possible ( 85 for shareholders' equity and 87 for net income), the average increase in shareholders' equity is equal to $7.11 \%$ and in net income is equal to $14.42 \%$. These findings are in line with the results gained from other analyses. Cordazzo (2008) discovered in her study a rise in shareholders' equity by $5.02 \%$ and in net income by $14.25 \%$. Similarly, Cortesi et al. (2009) observed that shareholders' equity (6.5\%) and net income $(15.5 \%)$ under IAS/IFRS are significantly higher than under Italian GAAP.

Therefore, it can be stated that there are only slight differences between the overall impacts on shareholders' equity and net income of IAS/IFRS in listed companies and medium-sized entities. The results show that the boost in shareholders' equity was mainly caused by IAS 38/36 (4.36\%), IAS 16 (3.26\%), and 
IFRS $3(1.02 \%)$, whereas IAS $12(-2.07 \%)$, IAS $39(-0.34 \%)$, and IAS $18(-0.23 \%)$ had a negative influence. The situation for net income is quite similar. There, the most important drives are IAS 38/36 (29.06\%), IAS 17 (4.55\%), and IAS $16(2.45 \%)$. Net income is negatively influenced by IAS $18(-8.67 \%)$, IAS $12(-5.61 \%)$, and IFRS $3(-5.12 \%)$. Even the results regarding the single standard impacts are in line with the findings of the cited papers and will be further discussed later in this section.

Figure 1 illustrates the relative frequency of the single IAS/IFRS impacts. It can be seen that IAS 19 (Employee Benefits) caused in over $80 \%$ of the analysed firms a variation in net income or shareholders' equity. Similar impact frequency can be observed by looking at IAS 38/36 (Intangibles) and IAS 12 (Income Taxes).

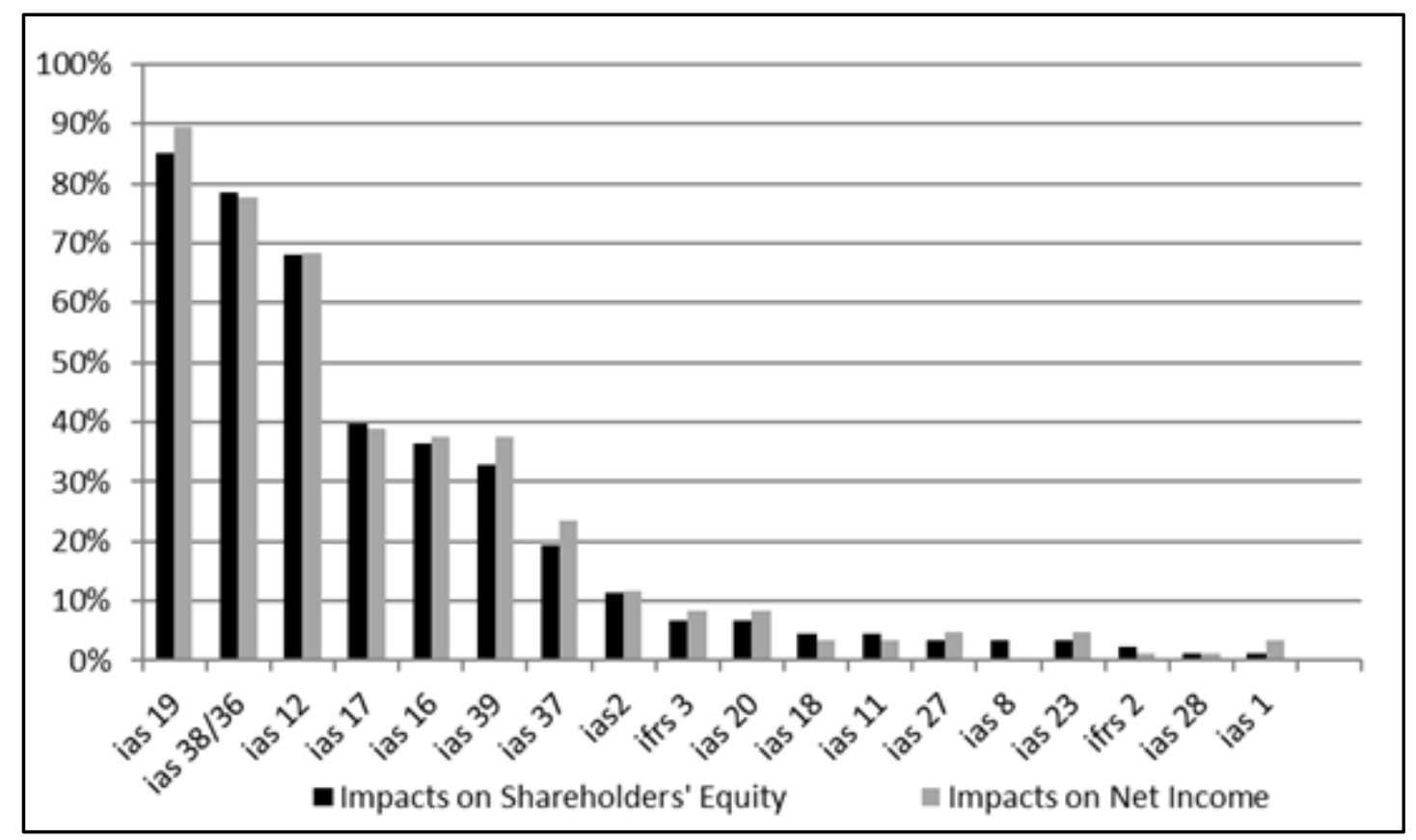

Figure 1. Frequency of single IAS/IFRS impacts.

IAS 17 (Leasing), IAS 16 (Property, Plant and Equipment), and IAS 39 have a lower level of frequency but still caused an adjustment in roughly every third analysed company. Marginal frequencies can be observed for IAS 37 and IAS 20, whereas other IAS/IFRS standards had rare impacts on analysed enterprises.

In the following pages, the result for each single standard will be discussed more in detail and a comparison towards other researches will be made. A primary benchmark consists of the results gained by the study of Cortesi et al. (2009) who undertook the same study with reference to listed companies. Moreover, the results shown by Cordazzo (2008) will be used as reference point even though a comparison with these figures is limited. This limitation concerns slight differences in the calculation process. Cortesi et al. (2009) and the present study calculated the variation, assuming as basis-value Italian GAAP figures, whereas Cordazzo (2008) in the calculation of the partial index of proportionality used IAS/IFRS values as basis. These differences in the calculation process are small and insignificant when variations are relatively low. The greater the relative differences between Italian GAAP and IAS/IFRS amounts are, the higher is the impact of the different calculation process. As most differences found in the study are relatively small, this fact does not play a significant role. Even Cordazzo (2008) herself totally neglected this difference in the calculation process when discussing her results. Therefore, it will not be further analysed, but still it is important to remember that small 
differences in the results may derive from this fact. Moreover, it is not the aim of this study to analyse the differences in the single percentage values obtained from the different studies. The confrontation to other results should lead to discovering general trends, similarities, and differences whereat the exact amount of the single percentage plays a secondary role.

\section{IAS 38: Intangible Assets}

As shortly stated above, the application of IAS 38 (Intangible Assets) caused relevant and frequent adjustments in the analysed companies' financial statements. On average, this single accounting standard leads to an increase of shareholders' equity by $4.36 \%$ and of net income by $29.06 \%$. These amounts included the impacts of IAS 36 (Impairment Test), which were carried out for intangible assets. Given those relevant adjustments, IAS 38 is considered, especially with reference to net income, as one of the standards causing the most important/relevant impacts. Similar results are shared also by the study of Cortesi et al. (2009) which proved that IAS 38 on average caused an increase of shareholders' equity by $3.5 \%$ and of net income by $14.9 \%$. Analysing the study of Cordazzo (2008), it can be seen that this study obtained significantly different results (Net income: $+1.89 \%$; Shareholders' equity: $-0.2 \%$ ). By looking closer at the single calculation process, a different treatment of the cancelation of goodwill amortisation costs can be observed. Cordazzo (2008) considered this adjustment is to be related to IFRS 3, whereas Cortesi et al. (2009) and also this study attribute this modification to IAS 38. Both standards define that goodwill is not amortised and that at least an annual impairment test has to be made. Neither one nor the other treatment seems to be incorrect, but by adopting a more literary interpretation to the standard, it seems that IFRS 3 covers more the initial determination and treatment of goodwill and not the following amortisation process.

Moreover, goodwill is still a fragment of the intangible assets with undefined lifetime, which are generally related to IAS 38. At least from a practical point of view, in the analysis of the financial statements, it was not always possible to clearly evidence which part of the variation of intangible assets was due to the cancelation of the amortisation cost of goodwill. So to provide more accurate information, this specific cancellation was added to IAS 38. Considering this different treatment, it can be seen that the stated differences between the values provided by Cordazzo (2008) and Cortesi et al. (2009) are not that different. By summing up IAS 38 and IFRS 3 values, it results that Cordazzo (2008) found a joint impact on net income equals to $14.37 \%$ and on shareholders' equity equals to $2.62 \%$. The joint impacts found by Cortesi et al. (2009) are $14.00 \%$ on net income and $3.2 \%$ on shareholders' equity. In addition to this mentioned difference, it can be seen that the impact on net income observed in this study is significantly higher than that found by Cordazzo (2008) and Cortesi et al. (2009). The reasons for such a gap are not easy to define. It may be related to the medium-sized companies, where the proportion between net income and amortisation cost of goodwill tends to be smaller than for listed companies. In other words, operations such as merger \& acquisitions and the so created goodwill tend to have a more relevant impact on financial statements of medium-sized entities than of listed companies. To clearly evidence the nature of the observed difference, further analysis would be necessary.

Besides these relevant impacts, IAS 38 was also one of the standards that caused the most frequent adjustments. Shareholders' equity experienced in 66 of 85 analysed companies a variation caused by IAS 38 and net income in 68 of 87 companies. Similarly, Cortesi et al. (2009) and Cordazzo (2008) discovered that IAS $38 / 36$ provoked the most frequent adjustments, which were presented in over $80 \%$ of the analysed enterprise. 
In general, the main reasons for these relevant and frequent impacts are due to the differences between Italian GAAP and IAS/IFRS, which were shortly stated in Section 2 of this paper. As experienced in the undertaken analysis, a relevant part of these impacts concerns the capitalisation of cost. Research and development costs, for example, can be alternatively capitalised or expensed according to Italian GAAP. IAS 38, in contrast, requires research cost to be expensed and development cost (given certain criteria) to be capitalised and amortised. The capitalisation and their amortisation had a relevant impact in many analysed enterprises. According to Italian GAAP, development costs are amortised over five years when capitalised. IAS 38 requires the amortisation of this capitalised cost over the useful life, which as experienced in the analysis often is larger than five years. As a consequence, annual amortisation rate under IAS 38 is smaller than under Italian GAAP. Therefore, with the adoption of IAS 38, exceeding amortisation cost had to be cancelled which caused a positive effect on net income and shareholders' equity. The different treatments of intangibles with undefined lifetime (goodwill) caused exactly the same effect. These assets according to IAS 38 are not amortised but annual impairment tests have to be carried out. Italian GAAP, on the other hand, requires the amortisation of all intangible assets and goodwill for instance has to be amortised over five years (under certain conditions up to maximal 20 years $^{2}$ ). The consequence is a cancelation of amortisation cost, which leads to an increase in net income and shareholders' equity. Another common adjustment caused by the adoption of IAS 38 concerns the cancelation of intangible assets. The definition of intangible asset required by IAS 38 is more rigorous than under Italian GAAP. The consequence is that by adopting IAS, some elements which do not meet the IAS criteria have to be cancelled out, which means that their amortisation has also to be cancelled.

\section{IFRS 3: Business Combinations}

According to the results obtained from the analysis, the application of IFRS 3 caused an overall increment of shareholders' equity by $1.02 \%$ and a decrease in net income by $5.12 \%$. As explained above, the adjustments accounted to this standard do not include the cancelations of amortisation of goodwill since this impact was accounted to IAS 38. The results gained for IFRS 3 include in this case the different regulations between IFRS 3 and Italian GAAP concerning the recognition of goodwill and business combinations in general. It has to be stated that the overall effect of IFRS 3 on net income and shareholders' equity is not significant. Furthermore, by looking at the frequency provided by Table 5 and Figure 1, it can be seen that the impact of this accounting standard can be neglected. Nevertheless, it has to be reminded that as stated above, a relevant part of adjustments connected to IFRS 3 is accounted for IAS 38. By not doing so, as did for example Cordazzo (2008), the frequency and even the impact of IFRS 3 would be significantly stronger. Therefore, the result obtained for IFRS 3 should not be valued isolatedly, but with reference to IAS 38 figures.

\section{IAS 19: Employee Benefits}

As shown in Table 5 and Figure 1, IAS 19 was the standard that caused the most frequent adjustments. The adoption of indicated norm had an impact on shareholders' equity in 76 of 85 analysed firms and on net income in 74 of 87 analysed firms. Same results are provided by Cordazzo (2008) and Cortesi et al. (2009) which observed an impact caused by IAS 19 by over $80 \%$ of the analysed enterprises. Although this standard caused the most frequent adjustments, its impact on the change in net income and shareholders' equity was relatively insignificant. The results show that after the adoption of IAS 19 (Employee Benefits), shareholders'

\footnotetext{
${ }^{2}$ In the time when most analysed companies adopted IAS/IFRS, the maximum was 10 years.
} 
equity $(+0.38 \%)$ and net income $(-0.51 \%)$ did not experience a significant change. Although the results provided by Cordazzo (2008) and Cortesi et al. (2009) ${ }^{3}$ at a first look presented a different direction, both papers conclude that the variation caused by IAS 19 is not significant.

The frequent but not significant adjustments derive from the different treatments of the reserve for employee termination indemnity (TFR). Italian GAAP requires this liability to be recorded at nominal value and measured according to the regulations of the Civil Code. IAS/IFRS regulation requires the calculation on actuarial assumptions consistent with the principle that employee benefits are recognised in the period in which the benefit is gained by the employee and not when it is paid. The differences deriving from the application of actuarial calculations are recorded as cost or revenues in the financial statements ${ }^{4}$.

As experienced in the analysis, no clear pattern can be observed. This fact is proved by Cordazzo (2008), who showed that the vast majority of the adjustments made according to IAS 19 had an impact of $\pm 5 \%$, whereas neither positive nor negative values prevailed.

\section{IAS 12: Income Taxes}

The results gained from the research evidence a significant impact of IAS 12 on shareholders' equity $(-2.07 \%)$ and on net income (-5.61\%). Also in terms of impact frequency, IAS 12 is among the most common standards, with an observation in roughly $70 \%$ of the analysed companies. The negative impact of IAS 12 , although not as substantial, is confirmed by Cordazzo (2008), who observed a slight decline in shareholders' equity by $0.19 \%$ and a decrease of net income by $2.92 \%$. Moreover, this study states that IAS 12 had an impact in nearly $75 \%$ of the observed enterprises. Cortesi et al. (2009), without giving further explanation, did not consider IAS 12 in the analysis.

The Italian OIC 25 "imposte sul reddito" generally conforms with the regulation of IAS 12 (Income Taxes) and therefore no relevant impacts due to differences in regulation have been observed. As Cordazzo (2008, p. 18) stated, the measurement of IAS 12 "includes the combined effect of the net impact of deferred taxes on IAS/IFRS adjustments and on other differences between Italian accounting principles and IAS/IFRS concerning the recognition of deferred tax assets and liabilities".

It is difficult to evidence the reasons for the gap in the results obtained from the different studies. As evidenced above, the measured adjustments under IAS 12 are not a consequence of the direct impact of different regulations between IAS 12 and Italian GAAP but the consequence of the modifications according to other IAS/IFRS standards. Since the impacts of IAS 12 are merely the consequences of adjustments driven by other standards and there exist only marginal differences between the regulation of this regard under full IFRS, Italian GAAP and IFRS for SMEs, IAS 12 will not be further discussed in this paper. This approach is in line with the procedure used by Cordazzo (2008) and Cortesi et al. (2009).

\section{IAS 16: Property, Plant and Equipment}

According to the results gained from the undertaken analysis, the application of IAS 16 (Property, Plant and Equipment) caused on average an increase of shareholders' equity by $3.26 \%$ and a similar rise in net income by $2.45 \%$. These findings are consistent with the results found by the two benchmark papers. Cortesi

\footnotetext{
${ }^{3}$ Cordazzo (2008) observed a decrease in shareholders' equity by $0.6 \%$ and an increase in net income by $2.52 \%$; Cortesi et al. (2009) found a marginal decline in shareholders' equity by $1.7 \%$ and an increase in net income by $0.7 \%$.

${ }^{4}$ For the recognition itself, more options are possible: immediate recognition through other comprehensive income, immediate recognition through profit or loss, deferred recognition (corridor approach).
} 
et al. (2009) found an increase in shareholders' equity by $2.7 \%$ and in net income by $1 \%$. The results provided by Cordazzo (2008) show a respective rise of shareholders' equity by $4.83 \%$ and of net income by $3.27 \%$. All three researches, besides slight differences in the amount, point out a positive impact of IAS 16 (Property, Plant and Equipment) on net income (on average around 2\%) and shareholders' equity (on average around 3.5\%), whereat the impact on shareholders' equity in all three studies resulted marginally stronger than on net income. In terms of frequency, the present research provides a lower level as observed by Cordazzo (2008) and Cortesi et al. (2009). Whereas the benchmark papers observed an impact frequency of IAS 16 above $60 \%$, this study experienced an incidence around roughly $40 \%$.

The observed impacts on shareholders' equity and net income derive from different accounting treatments of property, plant and equipment required by Italian GAAP and IAS 16. As observed in the study, an important aspect concerns the use of the fair value recognition allowed by international accounting standards. As it can be seen, many enterprises used the adoption of IAS to revalue their property, plant and equipment by applying the fair value method. Since the values under Italian GAAP were mostly recorded at historical cost, the adoption of fair value measurement caused a relevant positive impact on the value of the single property, plant and equipment and on the other side on shareholders' equity. Another common and significant impact was observed concerning the depreciation of land. Under Italian GAAP, it is possible to depreciate land together with the related buildings classified under property, plant and equipment. A similar treatment and the depreciation of land in general are not permitted according to IAS 16. The related adjustments when switching to IAS regulation had a positive impact on net income and therefore also shareholders' equity due to the cancelation of amortisation expense previously recorded. Moreover, impacts on net equity, due to the re-estimation of useful life and the application of pro rata calculation for the determination of deprecation cost, were observed several times.

\section{IAS 37: Provisions, Contingent Liabilities and Contingent Assets}

As shown by Table 5, the application of IAS 37 (Provisions, Contingent Liabilities and Contingent Assets) did not cause relevant overall impacts on shareholders' equity $(+0.19 \%)$ and on net income $(-0.22 \%)$. Even with respect to frequency, this IAS plays a minor role, as it causes an adjustment in only approximately $20 \%$ of the analysed companies. The comparison to the benchmark papers points out that the impact of IAS 37 on listed Italian companies was more frequent and more relevant. With respect to shareholders' equity, figures tend to be equal in all three analyses, observing a remote increase between $0.1 \%$ and $0.2 \%$. The situation differs when it comes to net income. In contrast to the findings provided by Table 5, Cordazzo (2008) and Cortesi et al. (2009) provided a significantly stronger decrease of net income by $2.7 \%$. The gap in the results can be partially explained by looking closer at the single impacts of IAS 37 .

In general, provisions for contingencies according to Italian GAAP concern futures cost whose existence is certain or probable, but whose occurrence or amounts cannot be measured reliable. The amount of the provision is determined on an undiscounted basis. The issue is treated slightly different under IFRS. IAS 37 requires that in order to recognise provision a present obligation has to exist. As described above, as a consequence of this fact, some provisions may have to be cancelled as they do not meet the new criteria. The results are an increase in net income and shareholders' equity. Furthermore, IAS 37 requires that provisions should be recognised at discounted estimated cost on the basis of the companies' adjusted risk-free rate and the amount of the provision should be reviewed and in case adjusted at each balance sheet day. As observed in the undertaken study, especially these adjustments of the provision caused common modification. 


\section{IAS 39: Financial Instruments: Recognition and Measurement/IAS 32: Financial Instruments: Disclosure and Presentation}

As evidenced by the results of the undertaken analysis, the impact of the adoption of IAS 39 and IAS 32 on the financial statements of Italian medium-sized entities is relatively moderate. As a consequence of the adoption of these standards, both shareholders' equity and net income experienced a remote decrease of approximately $0.35 \%$. Even if the impact frequency is relatively significant - each third analysed company recorded an adjustment caused by IAS 39/32 - the overall impact is not meaningful. This implies, as experienced also during the analysis, that frequent but rather small adjustments were made. These results present one of the most important differences with respect to the findings obtained by the benchmark papers. Cortesi et al. (2009) who also measured the combined effect of IAS 39 and IAS 32 observed an overall decrease of net income by $10 \%$ and of shareholders' equity by $1.6 \%$. Similarly, Cordazzo (2008) observed a joint negative impact on net income by $13.7 \%$ and on shareholders' equity by $1.58 \%$. In general, it can be stated that in all three studies, the adoption of IAS 39 and IAS 32 tends to have negative impacts whereas the impact itself is significantly stronger for listed companies. Before explaining the details of this important gap in the results, it can be of use to identify first the general differences in the accounting treatment of financial instruments according to Italian GAAP and IAS/IFRS.

The evaluation of financial instruments under Italian GAAP depends strongly on the type of classification of the financial asset itself (four categories), which often stands in contrast to the IAS regulation. But without going to much in detail, the significant differences refer mostly to the accounting treatment and the respective measurement of hedging derivative instruments (effective part and ineffective part) and their recognition as derivative liabilities or assets in the financial statements. But differences derive not only from the evaluation of hedge derivatives. Italian GAAP, for example, requires that treasury shares are recognised as assets in the balance sheet of the financial statement and their eventual value fluctuations, as well as their gains and losses from resell, have to be recorded as gains or losses in the income statement. IAS 32, on the other hand, requires treasury shares to be directly recognised (as a decrease) in net equity as well as all related movements.

These observations combined explain the vast majority of the adjustments observed in the three different researches. As the reasons for the adjustments tend to be similar in all three research papers, the reasons of the differences between the results gained by this study and those of the benchmark papers have to lie in the different characteristics of the analysed companies. As the present study refers to medium-sized entities, it can be assumed that financial activity in general has a minor relevance than in global connected listed companies. Especially what concerns the trading of complex financial instruments such as hedge derivatives, it is likely that it plays a much larger role in listed companies than in medium-sized entities. Obviously, the given explanation is based on assumptions, which are still to be proven. In order to be able to provide a well-grounded explanation of the given differences, further analysis would be required. The relationship of financial activity (or gains and losses) to overall activity (or overall result) could be measured in the samples used by the presented study and confronted to the relationship calculated for the sample used by Cordazzo (2008) or Cortesi et al. (2009). Based on the experiences gained from that analysis, it is likely that financial activity has a higher impact in the sample used by the benchmark papers. 


\section{IAS 17: Leasing}

As the results obtained by the study evidence, the adoption of IAS 17 causes a relevant impact of $+4.55 \%$ on net income, whereas shareholders' equity is affected only marginally at a rate of $+0.41 \%$. In terms of frequency, it has been observed that IAS 17 caused an impact on roughly $40 \%$ of the analysed enterprises. By confronting these amounts to the results obtained by the benchmark papers, it can be found that figures, especially with regard to net income, vary widely. Cordazzo (2008) found that IAS 17 caused no overall impact on net income (-0.04\%), whereas the impact on equity was positive at a rate of $1.6 \%$. Cortesi et al. (2009), on the other hand, discovered a negative impact of $0.4 \%$ for net income and shareholders' equity. The stated impact frequency provided by both papers lies around $25 \%$. It is difficult to evidence the significant differences between the results. Even the gap between the figures provided by Cordazzo (2008) and Cortesi et al. (2009) cannot be explained clearly. Since both papers refer mainly to the same sample (listed Italian companies), they should reach similar results. Unfortunately, only a part of the difference can be explained by the slightly different calculation process mentioned earlier in these sections. As both papers do not provide more detailed information about the single impacts caused by IAS 17, it is so far impossible to evidence the nature of the difference. Probable explanation may be the fact that Cordazzo (2008) did not take into consideration outliers whereas Cortesi et al. (2009) did not apply such a restriction. Moreover, it has to be mentioned that even if both papers refer to the Italian companies listed on the MIB, it does not necessarily mean that both papers analysed exactly the same companies.

In order to provide possible reasons for the differences between the results obtained from this study and those of the benchmark papers, it is necessary to analyse the single impacts caused by IAS 17 . The modification itself was caused as described in the reconciliation statement by the redetermination of leasing.

According to Italian GAAP in presence of a finance lease, the form of the contract prevails over the substance. This means that the lease has to account the single payments to the lessor as expense in the income statement. The object of lease is recognised and depreciated in the lessors' financial statement.

Moreover, the lessor accounts the received payments as revenue in the income statement. By applying IAS 17, the situation changes significantly. If the criteria of a financial lease are met, the object of lease is recorded in the lease balance sheet and depreciated over the estimated useful lifetime. On the other side, a liability equal to the net present value of future lease payments is established. This liability is progressively reduced as the payments to the lessor (capital part) were made, and the interest part of the payment is accounted to the income statement. This change in the accounting procedure had positive effects in 22 of the 34 observed adjustments (for net income). The other 12 negative impacts derive mainly from the scenario where the positive effect of the cancelation of the leasing payment made so far had a minor impact than the negative effect on net income deriving from the increase of amortisation.

So by analysing the single adjustments, it can be seen that no clear pattern can be found. Therefore, it is difficult to offer a general statement whether IAS 17 has a positive or a negative effect on net income and shareholders' equity. The effect strongly depends on each single case and therefore the general impact depends strongly on the analysed companies. This may explain the differences in the results and shows, moreover, that in this case a confrontation of results that based on different samples has limited significance. 


\section{IAS 18: Revenue}

As Table 5 shows, the adoption of IAS 18 (Revenue) causes a relevant negative impact of $8.67 \%$ on net income and a significantly moderate adjustment of $-0.23 \%$ on shareholders' equity. IAS 18 is therefore the accounting standard, which caused the most significant decrease of net income. Surprisingly, this overall effect was caused by only five single adjustments. This means that the transition to this standard rarely provokes modifications, but when it does, the adjustments are quite remarkable. Similar results, even if slightly more moderate, are also found by Cortesi et al. (2009). Their research observed that the adoption of IAS 18 caused an adjustment in roughly $20 \%$ of the analysed companies' net income. Still, these modifications were able to cause a drop of net income by $4.6 \%$. Shareholders' equity respectively decreased by $1.9 \%$. Cordazzo (2008), on the other hand, did not provide results regarding the impact of IAS 18 on net income and shareholders' equity. The study provides only the observed impact frequency which for net income was $16 \%$ and for shareholders' equity $14 \%$. Unfortunately, there is no explanation why the impact of IAS 18 was not measured.

The stated impact is caused by the cancelation of dividends, the recognition of revenues, and the different treatments of multi-period services.

From the provided results and the respective definition, it can be seen that the adjustments made in accordance with IAS 18 refer to very specific issues. Considering that and the fact that the observed frequency is significantly low, it cannot be stated that the adoption of IAS 18 has any general effect on net income or equity. The only thing that can be observed, considering also the results gained by Cortesi et al. (2009), is that if IAS 18 causes an impact on net income or shareholders' equity, this impact tends to be negative, as for a more restrictive definition and treatment of certain revenues under IAS than under Italian GAAP.

\section{IAS 2: Inventories}

The results obtained from the analysis show that the adoption of IAS 2 does not cause any relevant impact on the examined accounting figures. Both net income and shareholders' equity experienced a slightly positive impact of $0.2 \%$ and $0.16 \%$, respectively. At the same time, the impact frequency of approximately $10 \%$ is relatively low. Cordazzo (2008) found in her study that IAS 2 had a more significant impact of $+5.77 \%$ on net income and $1.25 \%$ on shareholders' equity and caused an adjustment in nearly every 4th analysed company. Cortesi et al. (2009) measured IAS 2 (Inventories) in combination with IAS 11 (Construction Contracts). The joint effects of these adoptions were an increase of net income by $1.6 \%$ and of shareholders' equity of $0.4 \%$. The observed combined impact frequency lies around 30\%. Cortesi et al. (2009) did not provide any explanation why IAS 2 and IAS 11 were measured in combination. In the undertaken analysis, it was no problem to distinguish the impacts of the two different standards, so from a perspective of accuracy, it was possible to measure both standards separately. Similarly, Cordazzo (2008) did not measure the impact of IAS 11 (only frequency is provided) without giving further information. Given this lack of information, a detailed comparison of the obtained results is not possible. Nevertheless, it can be stated that in general, IAS 2 adoption can have a positive impact on net income and shareholders' equity. The main reason for such a positive impact can be attributed to the evaluation methods of inventory used under OIC and IFRS. As stated by Cordazzo (2008) and as observed in the study, companies which had applied LIFO valuation method to their inventories under IT-GAAP had to switch towards average cost or FIFO valuation when adopting IAS. In all cases observed in this study, the transition was made towards average cost method. As stated in Section 2 of this paper, the use of LIFO is not allowed under IAS. If prices tend to increase, as observed for most items in 
the last years, the value of inventory rises according to the transition from LIFO to average cost method. The result is a positive effect on net income and shareholders' equity. When prices fall, the impact is inverted. But not all observed adjustments were caused by this valuation method difference, but the analysis of the adjustments evidenced a relatively significant negative impact as a consequence of the fact that under IAS, some costs (in this case advertising cost) cannot be capitalised but have to be accounted to income statement. The consequence of this different treatment is that such capitalised costs have to be cancelled when adopting IAS which has a negative impact on net income.

To sum up, it can be stated that IAS 2 rarely caused any relevant impact in the financial statements of the companies analysed in this study. Therefore, it can be deduced that most of the sample enterprises used already FIFO or average cost method before adopting IAS. The few observed adjustments were mainly due to the fact that LIFO method had been applied previously. In this case, since prices generally tend to increase, it is likely that the impacts on net income and shareholders' equity are positive.

\section{IAS 11: Construction Contracts}

As provided by Table 5, it can be seen that the adoption of IAS 11 caused a remote decrease of net income by $0.73 \%$. Shareholders' equity on the other hand tends to be stable as the observed variation is only $-0.06 \%$. In terms of impact frequency, this standard plays no significant role, causing an impact in roughly $5 \%$ of the analysed companies. As stated above, it is not possible to compare the results to the benchmark papers, as Cordazzo (2008) did not consider this standard in her analysis and Cortesi et al. (2009) included it in the revelation of IAS 2 .

Looking at the accounting treatment of construction contracts, it can be stated that Italian GAAP is generally in accordance with IAS 11. The only bigger difference refers to the completed contract method which, according to IAS 11 Paragraph 32, is only allowed when the result of the construction contract cannot be estimated with reliability. Moreover, in Italy in practice arises a relevant problem concerning the presentation of inventories of construction contracts, valuated according to the percentage of completion method. Whereas under Italian GAAP, the recognition of inventories in such cases is allowed, IAS 11 does not consider such treatment. Since the outcome of the construction contract can be estimated with reliability, it is required to recognise revenues in accordance with the percentage of completion method directly in the income statement. Given the facts that the results were mainly driven by a single adjustment and that the impact frequency with only six observed adjustments is insignificant, it can be stated that in general there is no evidence that the transition towards IAS 11 causes relevant problems. Nevertheless, as described, there are some differences in the accounting treatment of construction contracts which may lead to changes in specific cases.

The following paragraphs refer to the results which have not been described yet. Since these adjustments in terms of impact frequency and in terms of impact relevance do not play a relevant role, the explanation will be of a more general nature. Moreover, these obtained results cannot be compared to other outcomes, since Cordazzo (2008) and Cortesi et al. (2009) did not measure and treat their impacts in their analysis. In order to provide a true and complete insight of the undertaken analysis, it is nevertheless important to mention even these issues.

\section{IAS 20: Accounting for Government Grants and Disclosure of Government Assistance}

As observed from the undertaken analysis, the transition towards IAS 20 does not cause any relevant impact on the focused accounting figures. On average, shareholders' equity experienced a variation of $+0.08 \%$ 
and net income of $+0.55 \%$. The impact frequency with only seven (for shareholders' equity) and six adjustments (for net income) is relatively low. The accounting treatment of governments' grants under Italian GAAP is in general in accordance with IAS 20. As observed in the analysis, differences may arise from the application of fair value measurement of grants obtained in future years or from the change of the proportion of grants allocated in each financial year.

\section{IAS 8: Accounting Policies, Changes in Accounting Estimates and Errors}

The results provided by Table 5 show that the adoption of IAS 8 caused a marginal decrease of shareholders' equity by $0.18 \%$ and of net income by $0.83 \%$. The impacts cannot be considered significant as the results were mainly driven by two single impacts. Overall impact frequency lies around $3 \%$. The observed adjustments concern the retrospective correction of errors and the accurate quantification of sanctions. In general, no relevant differences between IAS 8 and Italian GAAP can be observed.

\section{IAS 27: Consolidated and Separate Financial Statements}

The undertaken analysis shows that the transition towards IAS 27 determined no important impact on the specific accounting figures. In particular, shareholders' equity varied on a rate of $-0.02 \%$ and net income by $-0.18 \%$. The impact frequency of approximately $3 \%$ is not considered significant. The observed adjustments derived for example from the redetermination of the value of investments in controlled companies, or from the obligation of accounting for provisions concerning the losses of participating companies. As the present analysis focused only on separate financial statements, many of the differences between IAS 27 and Italian GAAP did not affect the results. The impact frequency found by Cortesi et al. (2009) and Cordazzo (2008) provided higher amounts, which can be explained by the fact that those papers refer to consolidated financial statements.

\section{IAS 23: Borrowing Costs}

The results obtained from the undertaken analysis show that the adoption of IAS 23 (Borrowing Costs) caused little impact on the financial statements of the analysed enterprises. With reference to shareholders' equity, four adjustments had been observed, causing a joint impact of $0.14 \%$. On the other hand, net income was affected by three adjustments which led to a marginal decrease of $0.23 \%$. The benchmark papers, which have analysed only the impact frequencies, found similar low incidences. The single impacts derive from the fact that IAS 23 considers that borrowing costs which are directly attributable to the production, acquisition or construction of a qualifying asset ${ }^{5}$ have to be capitalised. Such a capitalisation, given certain conditions, is allowed according to Italian GAAP, but not required.

\section{Discussion}

The present section aims to provide a further comparative analysis of the most important IAS drivers evidenced in Section 5. Those standards, regulated according to full IAS, are compared to the regulation according to IFRS for SMEs. By doing so, differences and similarities in the set of regulation can be evidenced and the results can be used to draw assumptions whether the experienced impacts would have occurred also by applying IFRS for SMEs. Finally, such an analysis should enable a judgment over the adequateness of the IFRS for SMEs to fit the special needs of SMEs.

${ }^{5}$ Qualifying asset: one that necessarily takes a substantial period of time to get ready for its intended use or sale IAS 23. 


\section{Intangible Assets and Goodwill}

As seen in Section 5, the differences in the accounting treatment of intangible assets and goodwill under IAS and Italian GAAP caused one of the most relevant impacts on net income and shareholders' equity. The undertaken analysis shows that the adoption of IAS 38, which covers the topic of intangible assets and goodwill, leads to a relevant increase of net income and shareholders' equity. In $80 \%$ of the analysed firms, this standard caused an adjustment to the focused accounting figures. Given this fact, it can be stated that IAS 38 is one of the most important standards related to this analysis.

Analysing the regulation of IFRS for SMEs with reference to intangible assets and goodwill, it can be seen that there are relevant differences with IAS 38 relating to the recognition criteria and valuation methods. A first gap refers to the treatment of research and development costs. According to Section 18.4 of the IFRS for SMEs standard, all development and research costs are recognised as expense. IAS 38, as discussed previously, requires development cost to be capitalised as certain criteria are met. Further differences are related to the subsequent measurement of intangible assets. According to Section 18.18, the only allowed method under IFRS for SMEs is the cost model. IAS 38 on the other side allows also the adoption of the revaluation method where intangible assets are carried at a revaluated amount less accumulated depreciation. According to depreciation, the IFRS for SME regulation requires that intangible assets can have only defined useful life and that they are depreciated over this period. If the useful life of intangible assets cannot be estimated with reliability, it cannot exceed 10 years. The regulation provided by IAS 38 divides intangible assets into intangible assets with defined useful life and intangible assets with undefined useful life. The first ones depreciate like under IFRS for SMEs, over their useful period. Intangible assets with undefined life instead are not amortised, but an annual impairment test has to be carried out. The impairment test under IFRS for SMEs regulation is required only when there are indications for a loss in value of intangible asset. According to the analysis undertaken in Section 5, relevant adjustments were related to the cancelation of intangible assets as they did not meet the new definition of intangible assets according to IAS 38. The definitions of intangible assets IFRS for SMEs and IAS 38 regulation are similar. As described above under IFRS for SMEs, there are no intangible assets with undefined life and all intangible assets are amortised. This is true also for goodwill which, according to Sections 19.22 and 19.23, is recognised as intangible assets and depreciated over useful life. If the company is not able to provide a reliable estimate of life, goodwill is depreciated over 10 years.

Given this difference, it seems that the IFRS for SMEs regulation in many cases is more similar to Italian GAAP than full IFRS is. Many of the stated differences which have occurred by adopting IAS 38 would not have arisen, if the enterprises would/could have adopted IFRS for SMEs regulation. Since goodwill, similar to Italian GAAP, under IFRS for SMEs is amortised over expected useful life, the impact of transition from national to international accounting standards would not have had such a relevant impact on net income and shareholders' equity. Even the impacts concerning the differences in the accounting treatment of development cost would not have occurred. On the other side, given the similar definition of intangible assets according to full IFRS and IFRS for SMEs, it can be assumed that the positive impact on net income and shareholders' equity, deriving from the cancelation of intangible assets and their amortisation, would have occurred also by adopting IFRS for SMEs. Considering this single effect from a unique perspective, it can be assumed that the adoption of IFRS for SMEs with reference to intangible assets and goodwill would have positively affected net income and shareholders' equity. It is probable to assume that this impact would be of a more moderate nature, 
since it is likely that the most relevant adjustments, due to the cancelation of amortisation of intangible assets with undefined useful life (goodwill included) observed in the undertaken analysis, would not have occurred.

Given these differences in the accounting treatment of intangible assets and goodwill, it can be stated that the IFRS for SMEs regulation presents slight simplifications. Especially the fact that impairment test does not have to be carried out annually, as required by full IFRS, implies less bureaucratic efforts for the SMEs. Similarly, the reduction of options under IFRS for SMEs regulation, such as the fact that the cost model is the only allowed method to evaluate intangibles assets, decreases some accounting burdens. To sum up, it can be said that due to the fact that IFRS for SMEs in this specific issue is more similar to Italian GAAP than full IFRS is, the international standards explicitly designed for SMEs would present a valuable option. Due to the stated fact, it can be assumed that even the transition process towards an international standard-setting would be less onerous.

\section{Employee Benefits}

Given the results gained from the undertaken research, it was highlighted in Section 5 that the accounting treatment of employee benefits according to IAS 19 caused the most frequent adjustments. As seen, such adjustments were observed in over $85 \%$ of the analysed financial statements. Even though the overall impacts of these modifications were relatively moderate, IAS 19 can be considered as an important factor in present issue and has therefore to be analysed further.

The accounting treatment of employee benefits is regulated in Section 28 of the IFRS for SMEs. Analysing this section, it can be seen that most of the issue is regulated in accordance ith IAS 19. Especially with respect to the recognition and measurement of the employee termination indemnity, which as seen in Section 5 caused relevant adjustments, IFRS for SMEs and full IFRS regulations are quiet similar. Nevertheless, some particular issues are treated differently with respect to IAS 19. Full IFRS, for example allows, according to IAS 19, that actuarial losses or gains can either be accounted immediately to income statement or amortised (into loss or profit) over the expected working lives of the employee. Section 28 of the IFRS for SEMs requires, on the other hand, that such actuarial gains or losses have to be recognised immediately. Another difference arises from the valuation methods permitted for calculating the defined benefits obligation. IAS 19, as seen in Section 5, prescribes the use of the project unit credit method to evaluate benefits obligations on an actuarial basis. According to the IFRS for SME regulation, the circumstance-driven approach can be applied. This implies that the use of the project unit credit method is prescribed if the necessary information for the calculation process is available or can be obtained without further costs or efforts. Such information regards, for example, the estimation of the future rise in salary, the possible mortality rate or the expected remaining work life of the employee. If this information is not present or if it is costly to obtain such information, it is allowed to not consider them in the calculation process or to use the best estimate available.

As seen in Section 5, the main differences between Italian GAAP and IAS 19 derived from the accounting treatment of the employee termination indemnity, which under Italian practice is valuated at nominal value and not on an actuarial basis. As shortly stated above, regulation of full IAS and IAS for SMEs in this issue are quite similar. Therefore, the assumption can be made that most of the adjustments related to IAS 19 observed in the analysis would have occurred even by adopting IFRS for SMEs even if the amount of the impacts itself may vary slightly due to the simplifications of the calculation process available for SMEs. 
In a nutshell, it can be said that the simplifications presented by Section 28 of the IFRS for SMEs are able to facilitate, in some cases, the calculation process of the determination of the benefits obligations. Nevertheless, the accounting treatment of employee benefits in general remains significantly more complicated than under Italian GAAP. The fact that on the basis of IAS calculation process stands in both cases an actuarial evaluation method implies that most SMEs would be confronted to relevant problems when adopting international standards.

\section{Property, Plant and Equipment}

The accounting treatment of property, plant and equipment results to be a relevant factor in the present analysis. As observed in Section 5, the application of IAS 16 caused relevant and frequent adjustments and therefore contributed significantly to the overall change in net income and shareholders' equity. As discussed, these overall positive impacts were mainly caused by the possibility allowed by IAS 16 to adopt the revaluation method for the subsequent measurement of the intangible assets. This option enables firms to carry their property, plant and equipment at their revaluated amount, which is equal to fair value less subsequent depreciation and impairment. By analysing the accounting treatment required by Section 17 of the IFRS for SMEs, it can be seen that the only method allowed for the subsequent measurement of property, plant and equipment is the cost model, where those assets are carried at historical cost less accumulated depreciation and impairment losses. This fact presents one of the major differences between full IAS and IFRS for SMEs with a relevant effect also on the outcome of this analysis. Further differences concern the initial measurement of tangible assets. IAS 16 prescribes that if the recognition criteria are met, property, plant and equipment should be capitalised. On the other hand, IFRS for SMEs in Sections 17.9-17.11 prescribes that property, plant and equipment is measured as initially cost which consists of the following factors:

(1) Purchase price;

(2) Directly attributable costs which were necessary to bring the assets in the condition and location for its use;

(3) Initial estimate of costs of dismantling and removing the item and restoring the site on which it is located.

Borrowing costs are explicitly recognised as expenses and no capitalisation is allowed. With reference to other aspects concerning the accounting treatment of intangible assets, no particular differences can be observed. Even the handling of land, full IFRS and IFRS for SMEs regulation are similar. As been observed in the undertaken analysis, common adjustments derive from the fact that according to Italian GAAP, land can be depreciated in combination with the building situated on in. This procedure and the depreciation of land in general are not allowed under full IFRS or under IFRS for SMEs.

To sum up these differences and similarities, it can be assumed that a vast majority of the experienced effects deriving from the application of IAS 16 would not have occurred, if the analysed enterprise would have and could have adopted IFRS for SMEs. Similar to the case observed for intangible assets, the IFRS for SMEs regulation tends to be more similar to Italian GAAP than full IFRS. Especially, the impacts deriving from the possibility to apply revaluation method (which accounted for the majority of the observed impacts) would not have occurred by adopting IFRS for SMEs. The same is valid also for the treatment of borrowing cost. On the other hand, minor important impacts deriving for example from the depreciation of land would still be present. 
As seen above, the regulation provided by the IFRS for SMEs concerning the accounting treatment of property, plant and equipment includes some simplification. The most important facilitation regards the cancelation of the possibility to adopt the revaluating method. Since the determination of the fair value of a certain assets can be very costly, especially for SMEs, it is significantly easier to apply the cost model. It has to be pointed out that even under full IFRS, the revaluation model is just an option and not required and therefore the cancelation of this option under IFRS for SMEs cannot be considered as an effective simplification. On the other hand, the evaluation of assets according to fair value is an important factor even with reference to a true and faithful representation of the firms' economic situation. The main stakeholders, especially banks, would benefit from such a representation. Even though the application of the fair value option is more costly for companies switching towards IFRS, the undertaken research showed that a relevant part of the analysed companies made use of this option. From this fact, it can be deduced that benefits deriving from a fair value evaluation may offset the costs even in SMEs. Therefore, the absence of the option for the revaluation method in IFRS for SMEs regulation can be seen as a simplification but at the same time also as a useful tool to satisfy the firms' stakeholder needs.

\section{Leasing}

As seen in Section 5, the accounting treatment of leases was a relevant factor influencing significantly the overall results for net income and shareholders' equity. Besides the observed positive impacts on the focused accounting figures, especially on net income $(+4.55 \%)$, IAS 17 was the standard that caused the fourth most impact. As described, in approximately $40 \%$ of the analysed companies an adjustment related to leasing was found. These facts obviously identify the accounting treatment of leases as a crucial factor of the present analysis.

Comparing the regulation concerning leasing under IAS 17 with the IFRS for SMEs, no relevant differences can be observed. Section 20 of the IFRS for SMEs, which covers leases, is in vast part identical to the accounting treatment required by IAS 17. Small differences arise from the fact that according to IAS 17, inflation has to be considered when determining the operating leasing values. Inflation according to IFRS for SMEs has not to be considered in this calculation process. With reference to the overall impact of leasing, this small difference plays an irrelevant role.

As described in Section 5, the observed adjustments caused by IAS 17 concerned mainly the redetermination of financial leases and the related differences in the accounting treatment. As full IFRS and IFRS for SMEs regulation according to this issue do not vary, it can be assumed that the observed impacts would have also occurred if the analysed companies would have applied IFRS for SMEs. Moreover, no relevant differences between the accounting treatment of financial and operating leases exist under Italian GAAP. This, obviously, does not respect the principle of faithful representation, which requires that transactions should be accounted according to their true economic substance rather than their mere legal form. According to international standard, the cited principle plays a relevant role, which explains in this case the observed differences between IT-GAAP and IFRS for SMEs.

Summarising, it can be stated that IFRS for SMEs concerning the accounting treatment of leases contains just small irrelevant simplifications. This means that switching from Italian GAAP towards an international based accounting implies in both cases a more complicate treatment of the issues. This is not due to the fact that international standards in this specific case are remarkablely complicated and detailed, but due to the fact that Italian GAAP treats leases in a very simplified manner. 


\section{Financial Instruments: Recognition, Measurement Disclosure and Presentation}

The results provided in Section 5 show that the adoption of IAS 39 "Financial Instruments: Recognition and Measurement" and of IAS 32 "Financial Instruments: Disclosure and Presentation" had only a moderate impact (negative) on overall net income and shareholders' equity. Nevertheless, due to the relatively high observed impact frequency of over $30 \%$, it is important to confront the accounting treatment of financial instruments according to full IAS with IFRS for SMEs regulation in order to evidence respective similarities and differences.

By analysing the IFRS for SMEs regulation more in detail, it can be seen that there exist some differences in the accounting treatment of financial instruments. In general, IFRS for SMEs has two sections which deal with financial instruments. Section 11 addresses the accounting treatment of basic financial instruments, such as simple payables/receivables, cash or loans. Section 12, on the other side, regulates the application of more complex financial transactions and instruments. Therefore, referring to the nature of the financial instrument, the company should either apply to the single group of instrument, Section 11 or Section 12. Moreover, as presented by Sections 11.2 and 12.2, the company has the possibility to apply also the regulation provided by IAS 39. This fact presents one of the rare cases, where the IFRS for SMEs standard, which is generally considered a stand-alone standard, refers to full IFRS regulation. IAS 39, on the other hand, distinguishes four categories of financial instruments:

(1) Financial assets of financial liabilities at fair value through profit or loss;

(2) Held-to-maturity investments;

(3) Loans and receivables;

(4) Available-for-sale financial assets.

The initial measurement of basic financial instruments is based on the transaction price. Similarly, IAS 39 requires initial recognition to be based on fair value which is normally the transaction price. Differences arise with respect to the subsequent measurement. Basic debt instruments are measured according to IFRS for SMEs at the end of each reporting period, at amortised cost, applying the effective interest method. Other basic instruments such as commitments to receive a loan are recognised and measured at cost less eventual impairment. Investments such as non-convertible and non-puttable shares are valued at fair value or cost, depending on whether fair value can be measured reliably. The subsequent measurement of financial instruments according to IAS 39 depends strongly on the classified group. Financial instruments held for trading are carried at fair value through profit or losses, held-to-maturity investments are recognised at amortised cost, the same is required for loans and receivables. Financial assets available for sale are measured at fair value through equity. The determination processes of amortised cost, effective interest method and fair value evaluation are similar under both regulations. Furthermore, small differences can be observed with reference to the impairment of financial instruments and the de-recognition process. In the undertaken analysis, it was observed that the accounting treatment of hedged derivatives and the respective measurement caused frequent adjustments. With respect to this issue, IAS 39 and Section 12 of the IFRS for SMEs regulation tend to be similar. Small differences derive from the fact that according to IFRS for SMEs, the possibility for hedging derivative is more restricted.

To sum up, it can be stated that the IFRS for SMEs regulation concerning financial instruments is in vast part similar to full IAS regulation. Relevant differences concern mostly the classification and the subsequent measurement of financial instruments. The present differences derive from a slightly simplified accounting treatment allowed by Sections 11 and 12 of the IFRS for SMEs. This simplification concerns especially basic financial instruments, whereas the regulation for more complex issues tends to be more similar. With reference 
to the observed impacts in Section 5, it can be assumed that a vast majority of the found impacts would have also occurred under IFRS for SMEs regulation, since the issues which caused the most frequent modifications are treated similarly under IAS for SMEs and IAS 39.

As it can be observed in the results gained from the undertaken analysis, the standards which have not been mentioned in this section yet, had little or no influence on the overall outcome of this analysis. Even if standards such as IAS 18 or IFRS 3 realised relatively high variations of net income or shareholders' equity they are not generally considered as crucial standards, since it is not possible to devote a general conclusion from results characterised by single impacts and low frequency. Moreover, by analysing the IFRS for SMEs regulation with reference to these standards, it can be seen that no particular differences arise. This is true for standards such as IAS 37 (Provisions, Contingent Liabilities and Contingent Assets), IAS 2 (Inventories), IAS 11 (Construction Contracts) and IAS 18 (Revenue). Therefore, it can be assumed that even with reference to the reasons of the single impact caused by the cited standards (such as the recognition of dividends according to IAS 18), the observed adjustments would also have occurred applying IFRS for SMEs regulation.

\section{Conclusion}

The present study has analysed the effects of the adoption of IAS/IFRS on net income and shareholders' equity of Italian medium-sized entities. In order to gain valuable results, the financial statements of 94 Italian companies, which met the applied selection criteria, have been analysed. In particular, the study focused on the different reconciliation statements which have to be elaborated when transitioning from national GAAP towards international accounting standards.

Summarising the results gained from this analysis, it can be stated that the adoption of IAS/IFRS caused an average increase of net income by $14.43 \%$ and a respective rise in shareholders' equity of $6.27 \%$. These overall results are in line with the findings obtained from other studies, such as Cordazzo (2008) and Cortesi et al. (2009) which referred to Italian listed companies. So no relevant differences between the overall impacts on net income and shareholders' equity in listed and medium-sized companies could be found. Generally speaking, the observed adjustments derive mainly from the tax-driven nature of Italian GAAP and concern especially tangible/intangible assets, leasing, financial instruments, deferred tax recognition and employee benefits. Due to the analysis of the single reconciliation statements, it was furthermore possible to analyse the impact relevance and the impact frequency of each single IAS/IFRS standard. The results show that the most relevant and frequent impacts were caused by the adoption of IAS 38 (Intangible Assets), IAS 16 (Property, Plant and Equipment), IAS 19 (Employee Benefits), IAS 17 (Leasing), IAS 39 (Financial Instruments), and IAS 18 (Revenue). Comparing the results observed for the single standards to the findings obtained by similar studies, especially Cordazzo (2008) and Cortesi et al. (2009), some similarities but also a few differences arise. First of all, the impact relevance of IAS 38 seems to be much stronger in medium-sized than in listed entities. Reasons are assumed to be strongly related to the relevance the cancelation of the amortisation of intangible assets with undefined life (goodwill) has on net income. Secondly, the impact of IAS 39 and IAS 32, which refer to financial instruments, resulted to be less significant than observed in the benchmark studies. The differences may be explained by the fact that the observed adjustments refer to complex financial instruments, which are presumed to play a more significant role in listed than in medium-sized entities. Other smaller differences are related to the impacts of IAS 28 (Investments in Associates) or IAS 27 (Consolidated and Separated Financial Statements), which in contrast to results obtained by Cordazzo (2008) and Cortesi et al. (2009), in the present analysis caused no relevant adjustments. 
In addition to the empirical analysis of the financial statements, a short comparative study was carried out. The most important and significant international standards individuated in Section 5 (IAS 38, IAS 16, IAS 19, IAS 17, and IAS 39) were compared to IFRS for SMEs regulation in order to individuate similarities and differences in the accounting treatment. The results provided by this comparison show that no relevant differences exist in the accounting treatment of leasing, employee benefits, and financial instruments. Even with respect to less significant accounting standard, such as IAS 18 or IAS 11, no relevant discrepancies between full IAS and IFRS for SMEs regulation could be observed. The main differences individuated by the comparative analysis refer mainly to the accounting treatment of intangible assets and property, plant and equipment. With focus on these aspects, IFRS for SMEs regulation results to be more similar to Italian GAAP than full IFRS is. IFRS for SMEs, for example, requires that all intangible assets are amortised even if they have undefined life. IAS 38, on the other hand, does not consider that intangible assets with undefined life (goodwill) have to be amortised, but annual impairment tests have to be carried out. Furthermore, with reference to the subsequent measurement of property, plant and equipment, IFRS for SMEs does not permit the adoption of the revaluation method, which however is allowed by IAS 16. Due to the stated simplification, it can be assumed that the transition from Italian GAAP towards IFRS for SMEs would have caused more moderate adjustments for net income and shareholders' equity, than the adoption of full IFRS has caused.

So with reference to the individuated most relevant accounting standards, the IFRS for SMEs regulation provides only two significant simplifications. These facilitations may moderate the overall observed impact on net income and shareholders' equity, but still it can be assumed that the vast majority of the observed impacts would have occurred even when applying IFRS for SMEs. Consequently, it cannot be generally stated that IFRS for SMEs regulation provides significant simplification especially designed for the needs of SMEs. Therefore, from the present point of view, no relevant reasons for an adoption of IFRS for SMEs within the EU could be found. This position in an overall context seems to be shared also by the EU itself, which lately in several occasions dissociate themselves from the IFRS for SMEs blaming it to be in some cases not compatible with the 4th and 7th EU directives. According to these opinions, the success of the IFRS for SMEs, especially in emerging markets, is not to be based on the fact that this standard provides specific accounting treatments based on the need of SMEs, but can be merely explained by the fact that national GAAP in these countries are not able to guarantee a certain quality of accounting information.

The discussion of applying IFRS for SMEs within the EU seems to have come to an end, with the approval of the directive Number 34 of 2013. This direction, which at the moment has to be approved by the single member states, is going to replace the 4th and 7th European directives from 2016 on. With this directive, the European Commission aims to update the actual accounting principles valid within the EU, to nowadays requirements. Accounting standards within the EU are expected to be further harmonised and assimilated in many cases to the approach provided by international accounting standards. This harmonisation process is going to concern also and especially the accounting principles for SMEs. So despite approving the IFRS for SMEs standard, the European Commission decided to choose a bottom up approach of reviewing, modernizing, and harmonizing the accounting principles actually valid within the union. Based on the results gained from the undertaken study and on the available critical literature concerning IFRS for SMEs, the approach applied by the European Commission can be considered as the better alternative. 
In order to provide a faithful representation of the gained results, also the limitations and critical aspects of the undertaken analysis have to be mentioned. First of all, the significance of the results is limited by the fact that not all financial statements of the sample companies could be evaluated. Unfortunately, not all financial statements were available at AIDA and some did not contain the indispensable reconciliation statement. Nevertheless, it was possible to analyse a sufficient amount of companies in order to obtain general valid outcomes. In addition to this fact, it was possible to observe that the individuated sample was not perfectly homogenous. This means that in some cases, the overall results were significantly influenced by the adjustments applied in single companies. This fact shows that the definition of medium-sized entities given by the EU and applied by this analysis does not refer to a uniform group of companies but includes a wide range of enterprises with different dimensions.

Regarding the results obtained from the undertaken analysis, it has to be mentioned that since the present study, as known so far, is the first to analyse the impacts of IAS transition in Italian medium-sized entities, it was not possible to directly confront the findings with other papers. The used benchmark papers refer mainly to Italian listed companies and in some issues applied a slightly different calculation approach. Nevertheless, these papers were the only reference point available and even if certain limitations are given, the comparison was useful to evidence important similarities and differences. Furthermore, the applied research approach did not consider the level of compliance of the single companies. Therefore, eventual errors deriving from a wrong application of international accounting principles could eventually have influenced the obtained outcome.

Finally, it has to be stated that some issues raised by the findings of the undertaken analysis would merit a further and more detailed investigation. This concerns especially the individuated differences with references to the results obtained by the benchmark papers. By doing so, a well-founded explanation of the nature of the observed deviations could be provided.

\section{References}

Aisbitt, S. (2006). Assessing the effect of the transition to IFRS on equity: The case of the FTSE 100. Accounting in Europe, 3(1), 117-133.

Bae, K., Tan, H., \& Welker, M. (2008). International GAAP differences: The impact on foreign analysts. The Accounting Review, $83(3), 593-628$.

Baldarelli, M. G., Demartini, P., \& Mošnja-Škare, L. (2007). International Accounting Standards for SMEs: Empirical evidences from SMEs in a country in transition and in a developed country facing new challenges. Juraj Dobrila University of Pula, Department of Economics and Tourism "Dr. Mijo Mirkovic", Pula.

Barker, P., \& Noonan, C. (1995). Small company compliance with accounting standards: The Irish situation. The Institute of Chartered Accountants in Ireland.

Cole, V., Breesch, D., \& Branson, J. (2009). Are users of financial statements of publicly and non-publicly traded companies different or not? An empirical study. Retrieved from http://papers.ssrn.com/sol3/papers.cfm?abstract_id=1407566

Cordazzo, M. (2008). Principi contabili internazionali e risultati economici delle quotate italiane. Milano: Franco Angeli.

Cordazzo, M. (2013). The impact of IFRS on net income and equity: Evidence from Italian listed companies. Journal of Applied Accounting Research, 14(1), 54-73.

Cortesi, A., Montani, E., \& Tettamanzi, P. (2009). IAS/IFRS adoption by Italian listed companies: First empirical evidences. International Review of Business Research Papers, 5(4), 388-398.

Deaconu, A., Nistor, C. S., \& Popa, I. (2009). Analysis of the stakeholders' needs and their inference upon financial reports of SMEs. Journal of International Business \& Economics, 9(1), 39-52.

Deaconu, A., Popa, I., Buiga, A., \& Fulop, M. (2009). Conceptual and technical study regarding future accounting regulation for SMEs in Europe. Theoretical and Applied Economics, 1, 19-32.

Demartini, P. (2005). Accounting harmonization for European small business. Urbino: Quaderni di Economia Aziendale. 
Di Pietra, R., Evans, L., Chevy, J., Cisi, M., Eierle, B., \& Jarvis, R. (2008). Comment on the IASB's exposure draft 'IFRS for small and medium-sized entities'. Accounting in Europe, 5(1), $27-47$.

Dunne, T., Fifield, S., Finningham, G., Fox, A., Hannah, G., Helliar, C., Power, D., \& Veneziani, M. (2008). The implementation of IFRS in the UK, Italy and Ireland. Edinburgh: The Institute of Chartered Accountants of Scotland.

Eierle, B., \& Haller, A. (2009). Does size influence the suitability of the IFRS for small and medium-sized entities? Empirical evidence from Germany. Accounting in Europe, 6(2), 195-230.

Ernst \& Young. (2008). International GAAP 2008. London: John Wiley \& Sons, Ltd..

European Commission. (2010). Summary report of the responses received to the commission's consultation on the International Financial Reporting Standard for small and medium-sized entities. Brussels: European Commission.

Fifield, S., Finningham, G., Fox, A., Power, D., \& Veneziani, M. (2011). A cross-country analysis of IFRS reconciliation statements. Journal of Applied Accounting Research, 12(1), 26-42.

Grosu, V., \& Bostan, I. (2010). IAS/IFRS standards for SMEs and the impact on the Romanian accounting system. International Journal of Academic Research, 2(4). Retrieved from http://www.ijar.lit.az/pdf/6/2010\%284-41\%29.pdf

Hung, M., \& Subramanyam, K. (2004). Financial statement effects of adopting international accounting standards: The case of Germany. California: University of Southern California.

Ikäheimo, S., Ojala, H., Riistama, V., \& Stening, E. M. (2010). The IFRS for SMEs: Do we need it? Expert based study in Finland. Aalto University, School of Economics.

International Accounting Standards Board [IASB]. (2014). Comprehensive review of the IFRS for SMEs. London: IASB.

Jermakowicz, E. K. (2004). Effects of adoption of International Financial Reporting Standards in Belgium: The evidence from BEL-20 companies. Accounting in Europe, 1(1), 51-70.

Koumanakos, E., \& Alexandrou, G. (2010). Survey on the views of SMEs for IFRS in four countries. Ioannina: University of Ioannina.

KPMG. (2010). A comparison of "full IFRS" and IFRS for SMEs.

Marchal, S., Boukari, M., \& Cayssials, J. L. (2007). L'impact des normes IFRS sur les données comptables des groupes français cotés. Bulletin de la Banque de France, 163, 27-42.

Marra, A., Mazzola, P., \& Prencipe, A. (2011). Board monitoring and earnings management pre- and post-IFRS. The International Journal of Accounting, 46(2), 205-230.

Nobes, C., \& Parker, R. (2008). Comparative international accounting. Pearson: Harlow.

Organismo Italiano di Contabilità [OIC]. (2005). Guida operativa per la transizione ai principi contabili internazionali (IAS/IFRS). Roma: Organismo Italiano di Contabilità.

Ormrod, P., \& Taylor, P. (2004). The impact of the change to international accounting standards on debt covenants: A UK perspective. Accounting in Europe, 1(1), 71-94.

Paoloni, P. (2006). Il bilancio delle piccole imprese nella prospettiva internazionale. Turin: Giappichelli.

Pascu, A., \& Vasiliu, A. (2011). International financial reporting standard for small and medium-sized entities - A new challenge for the European Union. CES Working Papers, 3(1), 121-134.

PricewaterhouseCoopers [PwC]. (2008). Principi Contabili Internazionali Analogie e Differenze IFRS, US GAAP e Principi Italiani. PwC.

PricewaterhouseCoopers [PwC]. (2009). Similarities and differences: A comparison of "full IFRS" and IFRS for SMEs. PwC.

Quagli, A., \& Paoloni, P. (2012). How is the IFRS for SME accepted in the European context? An analysis of the homogeneity among European Countries, users and preparers in the European commission questionnaire. Advances in Accounting, 28(1), 147-156.

Sava, R., Marza, B., \& Esanu, N. (2013). Financial reporting for SMEs - Past and perspectives. Sibiu, Romania: Elsevier B.V.

Schiebel, A. (2007). Is there a solid empirical foundation for the IASB's draft IFRS for SMEs? Graz: Vienna University of Economics and Business Administration. 